\title{
EMMPRIN expression is associated with metastatic progression in osteosarcoma
}

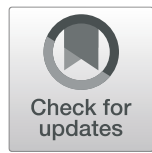

Han-Soo Kim ${ }^{1,2}$, Ha Jeong Kim¹, Mi Ra Lee ${ }^{1}$ and Ilkyu Han ${ }^{1,2^{*}}$ (D)

\begin{abstract}
Background: Extracellular matrix metalloproteinase inducer (EMMPRIN), a cell-surface glycoprotein, is overexpressed in several cancer types. EMMPRIN induces a metastatic phenotype by triggering the production of matrix metalloproteinase proteins (MMPs) such as MMP1 and MMP2, and vascular endothelial growth factor (VEGF) in cancer cells and the surrounding stromal cells. The purpose of this study was to investigate the expression and role of EMMPRIN in osteosarcoma.

Methods: The level of EMMPRIN expression was evaluated using reverse transcriptase polymerase chain reaction (RT-PCR) in 6 tumor-derived osteosarcoma cell lines and compared with that in normal osteoblasts. To study the prognostic significance of EMMPRIN expression, immunohistochemistry was carried out in prechemotherapy biopsies of 54 patients. siRNA knockdown of EMMPRIN in SaOS-2 cells was conducted to explore the role of EMMP RIN. To study the role of EMMPRIN in tumor-stromal interaction in MMP production and invasion, co-culture of SaOS-2 cells with osteoblasts and fibroblasts was performed. Osteosarcoma 143B cells were injected into the tail vein of BALB/c mice and lung metastasis was analyzed.

Results: EMMRIN mRNA expression was significantly higher in 5 of 6 (83\%) tumor-derived cells than in MG63 cells. $90 \%$ of specimens (50/54) stained positive for EMMPRIN by immunohistochemistry, and higher expression of EMMP RIN was associated with shorter metastasis-free survival $(p=0.023)$. Co-culture of SaOS- 2 with osteoblasts resulted in increased production of pro-MMP2 and VEGF expression, which was inhibited by EMMPRIN-targeting siRNA. siRNA knockdown of EMMPRIN resulted in decreased invasion. EMMPRIN shRNA-transfected 143B cells showed decreased lung metastasis in vivo.
\end{abstract}

Conclusions: Our data suggest that EMMPRIN acts as a mediator of osteosarcoma metastasis by regulating MMP and VEGF production in cancer cells as well as stromal cells. EMMPRIN could serve as a therapeutic target in osteosarcoma.

Keywords: EMMPRIN, Osteosarcoma, Matrix metalloproteinase, Invasion, Metastasis

\section{Background}

Osteosarcoma is one of the most frequent malignant tumors, which often appears in young persons and expresses high cancerous and metastatic potential [1, 2].

\footnotetext{
*Correspondence: hik19@snu.ac.kr

'Department of Orthopaedic Surgery, Seoul National University Hospital, 101 Daehak-ro Jongno-gu, Seoul 03080, South Korea

${ }^{2}$ Department of Orthopaedic Surgery, Seoul National University College of Medicine, Seoul, South Korea
}

Furthermore, it has been known to have a multiplied trend to metastasize $[1,3,4]$. The outcome for osteosarcoma patients with metastatic disease has not improved, thus, new therapies are essential [5]. The modulation of tumor suppressor genes and oncogenes is significant in the osteosarcoma progression [6-8].

Despite the enhancement of survival in patients with localized osteosarcoma, those with metastatic disease still carry a poor prognosis. As a result, identification of factors contributing to metastasis is needed. Biological

\section{BMC}

(c) The Author(s). 2021 Open Access This article is licensed under a Creative Commons Attribution 4.0 International License, which permits use, sharing, adaptation, distribution and reproduction in any medium or format, as long as you give appropriate credit to the original author(s) and the source, provide a link to the Creative Commons licence, and indicate if changes were made. The images or other third party material in this article are included in the article's Creative Commons licence, unless indicated otherwise in a credit line to the material. If material is not included in the article's Creative Commons licence and your intended use is not permitted by statutory regulation or exceeds the permitted use, you will need to obtain permission directly from the copyright holder. To view a copy of this licence, visit http://creativecommons.org/licenses/by/4.0/ The Creative Commons Public Domain Dedication waiver (http://creativecommons.org/publicdomain/zero/1.0/) applies to the data made available in this article, unless otherwise stated in a credit line to the data. 
characteristics of a malignant tumor are invasion and metastasis. The important step in the invasion and metastasis is the degradation of the extracellular matrix (ECM), and the matrix metalloproteinase proteins (MMPs) are the key players in the degradation of the ECM. Furthermore, the overexpression of MMP in malignancies is a contributing factor in metastasis, invasiveness, migration, and angiogenesis [9].

Extracellular matrix metalloproteinase inducer (EMMPRIN), known as basigin (BSO) and CD147, is a transmembrane glycoprotein of the immunoglobulin superfamily and plays manifold roles in physiological as well as in pathological conditions. It is strongly expressed in several types of cancers and activates adjacent stromal or tumor cells to induce matrix metalloproteinase (MMP). Additionally, EMMPRIN stimulates the vascular endothelial growth factor (VEGF) which is directly involved in angiogenesis. These findings suggest that EMMPRIN is an exciting therapeutic target in many cancer types. However, the role of EMMPRIN in the pathogenesis of osteosarcoma is unclear.

In this study, we assessed the levels of EMMPRIN gene expression and MMP activation in osteosarcoma cells from human samples and examined the role of EMMPRIN in the MMPs expression and invasiveness by EMMPRIN siRNA transfection. Our results suggest that EMMPRIN regulates MMP activation via tumor-stromal interaction and promotes invasiveness and metastasis in osteosarcoma. Furthermore, a current study confirmed that EMMPRIN silencing could inhibit osteosarcoma cell growth and invasion both in vitro and in vivo.

\section{Methods \\ Cell lines}

Osteosarcoma cells were isolated from four sources to be used in the investigations: [1] pre-chemotherapy tumor samples of 6 patients who underwent treatment in the authors' hospital from March 2003 to April 2004; [2] an established osteosarcoma cell line of Saos-2 (American Type Culture Collection (ATCC) Nu HTB85) [9]; [3] hFOB, from immortalized fetal osteoblasts (ATCC Nu CRL-11372) [10], and [4] MG-63 (ATCC Nu CRL-1427) [11]. All cell lines were purchased from the American Type Culture Collection, and cultured according to their guidelines [9-11]. Primary osteosarcoma cell lines were prepared as previously described in Kang et al.'s paper [12]. In brief, samples were minced and incubated at $37^{\circ} \mathrm{C}$ in DMEM with $0.2 \%$ proteinase (SigmaAldrich, St. Louis, MO) and $0.2 \%$ collagenase (Sigma-Aldrich, St. Louis, MO). The supernatant was filtered and centrifuged at $1500 \mathrm{rpm}$ for $5 \mathrm{~min}$. The cell pellet was re-suspended in DMEM with $10 \%$ fetal bovine serum (FBS) and seeded in $100 \mathrm{~mm}$ plates at $2 \times 10^{6}$ cells. After
3-5 days, the cells were sub-cultured. Second - or thirdpassage cells were selected for the experiments.

\section{Transfection and co-culture of SaOS-2 and hFOB}

SaOS-2 cells were cultured in MEM with Earle's salts or McCoy's 5A medium with 10\% FBS. For the experiments, cells were plated at density of $2.0 \times 10^{5}$ cells $/ \mathrm{cm}^{2}$ with medium changes done twice a week at $37^{\circ} \mathrm{C}$ in a humidified atmosphere with $5 \% \mathrm{CO}_{2}$. SaOS-2 cells were transfected with Silencer Negative Control siRNA (Life Technologies, Carlsbad, CA, USA) as a control and EMMPRIN siRNA (5'-UUC UGA CGA CUU CAC AGC CUU CAC U-3', Invitrogen, USA) using Lipofectamine-2000 (Invitrogen, San Diego, CA, USA). Cells were then incubated for $24 \mathrm{~h}$. hFOB cells were cultured in Dulbecco's modified Eagle's medium/F12 (DMEM/F12) supplemented with 10\% FBS and G418 (0.3 $\mathrm{mg} \mathrm{mL}^{-1}$, Gibco, Carlsbad, CA, USA) and maintained in a humidified atmosphere with $5 \% \mathrm{CO}_{2}$ at $34{ }^{\circ} \mathrm{C}$. The cells were digested with $0.25 \%$ trypsin and split at a 1:3 ratio. hFOB was used in the differentiation phase described by ATCC CRL 11372. Confluent hFOB cells were seeded above TransWell ${ }^{\circ} 12$ well inserts (Corning Costar Corporation, Cambridge, MA, USA) with a pore size of $0.4 \mu \mathrm{m}$ for incubation in conditioned medium. When hFOB monolayers were established, they were washed with DMEM. Supernatants from upper and the lower TransWell ${ }^{\triangleright} 12$ well chambers were separately collected at $24 \mathrm{~h}$.

Reverse transcriptase polymerase chain reaction (RT-PCR) To examine the expression of EMMPRIN mRNA in osteosarcoma, RT-PCR was performed in 6 osteosarcoma primary cell lines derived from prechemotherapy tumors of patients. Total RNA was extracted by TRIzol reagent (Invitrogen, Carlsbad, CA). RNA quantity and quality were assessed using the Nanodrop-ND-1000 (Nanodrop Technologies, Wilmington, DE, USA). cDNA was synthesized with the Reverse Transcription System (Promega, Madison, Wisconsin, USA). The primers for PCR amplification were: CD147, sense: 5'-GCAGCGTTGGAGGTTGT3', antisense: 5'-AGCCACGGATGCCCAGGAAGG3'; GAPDH (internal control), forward primer 50CATGAGAAGTATGACAACAGCCT-30, reverse primer 50-AGTCCTT CCACGATACCAAAGT-30. The cycling program was pre-set at $94{ }^{\circ} \mathrm{C}$ for $5 \mathrm{~min}$ for degeneration, and 30 cycles for $30 \mathrm{~s}$ at $94{ }^{\circ} \mathrm{C}, 55^{\circ} \mathrm{C}$ for $60 \mathrm{~s}$, and $72{ }^{\circ} \mathrm{C}$ for $30 \mathrm{~s}$, and finishing with for $10 \mathrm{~min}$ at $72{ }^{\circ} \mathrm{C}$ for elongation. The RT-PCR products were electrophoresed in $2 \%$ agarose gel with ethidium bromide [13]. 


\section{Gelatin Zymography}

The tumor microenvironment is critical for the proliferation and invasion of the tumor. Matrix metalloproteinases (MMPs) is crucial in the tumor microenvironment [14]. SaOS-2 cells and hFOB cells were plated in 6-well plates to either culture alone or in a co-culture system. For zymography analysis to detect MMP2 expression, cells were cultured in serum-free media for $48 \mathrm{~h}[15,16]$. Conditioned media were centrifuged and stored at $-70^{\circ} \mathrm{C}$. Protein lysates were prepared in $50 \mathrm{mM}$ Tris- $\mathrm{HCl}$ containing $150 \mathrm{mM} \mathrm{NaCl}$ and $0.1 \% \mathrm{NP}-40$ with $2 \mathrm{~g} / \mathrm{ml}$ pepstatin, leupeptin (Roche Diagnostics, Mannheim, Germany) and aprotinin (Sigma Chemical Co., St. Louis, MO). The gelatin zymograms were calibrated with gelatinase standard by capillary whole blood (Chemicon, Hampshire, United Kingdom). Staining of gels were done with $0.2 \%$ Coomassie brilliant blue R-250 (BioRad Laboratories, Hercules, CA, USA). Reconstituted lyophilized human pro-MMP2 was used as a positive control (Biotrak MMP2 activity assay kit, GE Healthcare). Gelatinase activity was observed as clear regions in blue gels. The bands were quantified considering both the intensity and the extension area, using an image analyzer system with ImageJ software version 1.49 (National Institutes of Health, Bethesda, Maryland, USA).

\section{Elisa}

EMMPRIN is known to stimulate tumor angiogenesis via VEGF $[17,18]$. To study the possible role of EMMP RIN in angiogenesis, we co-cultured osteoblasts and SaOS-2 cells. Quantitation of VEGF in co-culture supernatants was done using ELISA. Cells infected with mock siRNA were cultured in 6 -well plates $\left(1.0 \times 10^{5}\right.$ cells per well). After $48 \mathrm{~h}$, the medium was replaced with $1 \mathrm{~mL}$ of serum-free DMEM. After collecting the conditioned medium 3 days later, and the concentration of secreted VEGF protein was examined by ELISA kit (R\&D Systems, Minneapolis, MN, USA) [13].

\section{Western blotting analyses}

Transfected cells were incubated using fibronectin plate for $4 \mathrm{~h}$, and then lysed with buffer (NP-40 1\%, $150 \mathrm{mM}$ $\mathrm{NaCl}, 50 \mathrm{mM}$ Tris $\mathrm{pH} 7.5$, and proteinase inhibitor cocktail). Lysates were resolved by SDS-PAGE and then transferred onto nitrocellulose membrane. The membranes were probed with primary antibodies against EMMPRIN (Cell Signaling, \#13287S, Lot1) after incubating in a blocking buffer. The labeling was observed using peroxidase-conjugated secondary antibodies and an ECL kit (Pierce, Thermo Fisher Scientific, Waltham, MA, USA) [19].

\section{Matrigel invasion assay}

Invasion assays were performed using a BD BioCoat Matrigel Invasion Chamber (BD, New Jersey, USA) (pore size, $8 \mu \mathrm{m}$ ). EMMPRIN-siRNA-transfected SaOS-2 cells were introduced into the upper compartment in transwell chambers, and the lower compartment contained hFOB cells. Cells were incubated for $24 \mathrm{~h}$, fixed, stained with $0.5 \%$ crystal violet and then counted under light microscope.

\section{In vivo metastasis assay}

To test if EMMPRIN plays an important role in osteosarcoma metastasis in vivo, the osteosarcoma cell line $143 \mathrm{~B}$ was injected in the tail vein of BALB/c mice. The mice were sacrificed at 8 weeks post-injection. Fourweek-old male BALB/c nude mice were obtained from Central Lab. Animal Inc. (Seoul, Korea) and maintained under standard conditions until the experiments were performed. The animals were maintained at the animal facility of the Seoul National University Hospital under guidelines prior to the grouping and experiments. A total of $15 \mathrm{BALB} / \mathrm{c}$ nude mice were randomized into 3 groups: [1] normal, [2] 143 cells transfected with an ad mock shRNA vector (Control), and [3] 143 cells transfected with the ad EMMPRIN shRNA vector. Experiments were approved by the Institutional Animal Care and Use Committee of Seoul National University Hospital (approval number 10-0075). One anti-EMMPRIN sequence (5-GTCGTCAGAACACATCAAC-3) or a scrambled sequence was inserted into the plasmid vector pAdEasy-1 (Addgene). They were designated as pAdEasy-1-shRNA and pAdEasy-1 scramble shRNA, respectively. Osteosarcoma cell line 143B was transfected with EMMPRIN shRNA. EMMPRIN shRNA transfected 143B cells were harvested with trypsin, and then resuspended in serum-free RPMI, and injected in the tail vein $\left(1 \times 10^{5} / 0.2 \mathrm{~mL}\right)$ of 5 nude mice per group. Health of the animals was monitored daily, and body weights were measured weekly throughout the study period. Anesthesia was performed with isoflurane inhalation as well as ketamine $(10 \mathrm{mg} / \mathrm{kg})$ and medetomidine $(0.1 \mathrm{mg} /$ $\mathrm{kg}$ ) injection. All surgical procedures were performed under sterile conditions. Secondary euthanasia method for cervical dislocation was also performed. The mice were sacrificed by $\mathrm{CO}_{2}$ inhalation at 8 weeks postinjection. Harvested tissues were preserved in Bouin's fixative, embedded in paraffin, sectioned $(4 \mu \mathrm{m})$, and stained with hematoxylin and eosin (H\&E). Examination of the histological sections was performed using Nikon Eclipse Ci microscope (Nikon Corp., Tokyo, Japan) by a digital camera (Nikon digital sight, DS-2Mv) and the automatic exposure and iSolution Lite software for microscopic images. The tumor lengths and widths were measured by a perpendicular tumor diameter, with the 
tumor volume being calculated using the following formula: width $^{2} \times$ length/2 [20].

\section{Immunohistochemistry and clinical outcome}

To examine EMMPRIN expression in a larger cohort of patients, immunohistochemistry was performed in prechemotherapy osteosarcoma specimens from 52 patients. Pre-chemotherapy biopsy specimens were used to analyze the EMMPRIN expression by immunohistochemistry [21]. Osteosarcoma specimens derived from patients who underwent operation at Seoul National University Hospital with clinical annotation of more than 1 year follow-up were used. Briefly, $4 \mu \mathrm{m}$ sections in paraffin were de-paraffinized using xylene and rehydrated in alcohol solution. Antigen retrieval was performed by pretreating the slides in citrate buffer. To suppress binding of nonspecific antigen-antibody, tissues were treated with a blocking solution of $10 \%$ nonimmune serum and then incubated overnight with mouse monoclonal antibody of EMMPRIN (Abcam, \#ab188190, GR3250057-5) and stained with the avidin-biotinperoxidase complex method (Vectastain $\mathrm{ABC}$ kit, Vector Laboratories, Burlingame, CA). Staining reactions were interpreted with parallel-processed control slides consisting of esophageal cancer known to express EMMP RIN as the positive control, and with the negative control after replacing primary antibody with Tris-buffered saline [22]. The degree of EMMPRIN expression was evaluated by one of the investigators blinded to the patients' clinical data. The expression of EMMPRIN was semi-quantitatively assessed by the extent (not intensity) of staining. After finding the areas showing the most tumor cells at $\times 40$ magnificatio, cells were counted under $\times 100$ magnification. Samples were graded into high and low expression groups by the percentage of positively staining cells among tumor cells with a cutoff value of 50\% [23]. Examination of the histological sections was performed using Nikon Eclipse Ci microscope (Nikon Corp., Tokyo, Japan) and the automatic exposure and iSolution Lite software for microscopic images.

All patients had localized high-grade osteosarcoma of the extremities at the time of diagnosis. Standard treatment was given, consisting of neoadjuvant chemotherapy and primary resection followed by adjuvant chemotherapy. The response to chemotherapy was assessed according to the Huvos criteria [17]. Overall survival was defined as the time from osteosarcoma diagnosis to the date of either death or the last hospital visit. We defined metastasis-free survival as the time from osteosarcoma diagnosis to the development of metastasis. The minimum follow-up was 12 months (range, $12-110$ months; mean, 42 months). The mean follow-up of the survivors was 50 months. During the follow-up period, local recurrence was observed in 11 patients, and metastasis in 20 .
Fourteen of the 52 patients died of disease, 37 patients showed no evidence of disease, and 5 remained alive with disease at the last follow-up.

\section{Statistical analysis}

Statistical analyses were performed using the SPSS 12.0 software. Survival curves were calculated by the KaplanMeier method, with the differences in survival calculated using the log-rank test. Correlations between EMMPRIN expression and clinical factors were evaluated using Pearson's $\mathrm{x}^{2}$ test $(P<0.05)$. Uni- and multi-variate analyses were performed using the Cox proportional hazards model.

\section{Results \\ EMMPRIN mRNA expression in osteosarcoma cells}

The EMMRIN mRNA expression level was significantly higher in 5 of $6(83 \%)$ tumor-derived cells compared to MG63 (Fig. 1A, B). EMMPRIN mRNA and protein levels were significantly downregulated by siRNA transfection in comparison to control siRNA transfected cells (Fig. $1 C, D)$. siRNA ( $30 \mathrm{nM}$ ) was used for further experiments in terms of its lowest expression.

\section{EMMPRIN knockdown and MMP2 activity}

[23] To study the role of EMMPRIN in tumor-stromal interaction, we co-cultured SaOS-2 cells with osteoblasts (hFOB). Co-culturing of osteoblasts and SaOS-2 enhanced the stimulation of pro-MMP2. This stimulation was reversed by transfection of SaOS-2 cells with EMMPRIN-targeting siRNA (Fig. 2A). The grayscale ratio of MMP2 activity in co-cultures of $30 \mathrm{nM}$ EMMP RIN siRNA transfected SaOS-2 cells with hFOB cells was significantly lower than that of the control $(p=0.01)$ (Fig. 2B). These results show that EMMPRIN inhibition results in decreased MMP2 activity in co-cultures of SaOS-2 cells with hFOB cells.

\section{EMMPRIN knockdown and VEGF production}

$[17,18]$ VEGF expression was increased in the coculture compared to the SaOS-2-only culture. Transfection of SaOS-2 with EMMPRIN-targeting siRNA resulted in a decrease in VEGF expression (Fig. 3).

\section{EMMPRIN knockdown and invasion}

The invasion of SaOS- 2 cells treated with 0 and $30 \mathrm{nM}$ EMMPRIN siRNA was detected by the transwell chamber assay after treatment for $24 \mathrm{~h}$. The number of cells crossing the chamber were statistically lower in cells transfected with $30 \mathrm{nM}$ EMMPRIN-siRNA than in cells transfected with control-siRNA $(25.2 \pm 3.5$ cells vs. $5.0 \pm 1.4$ cells $P=0.048$ ) (Fig. 4). 

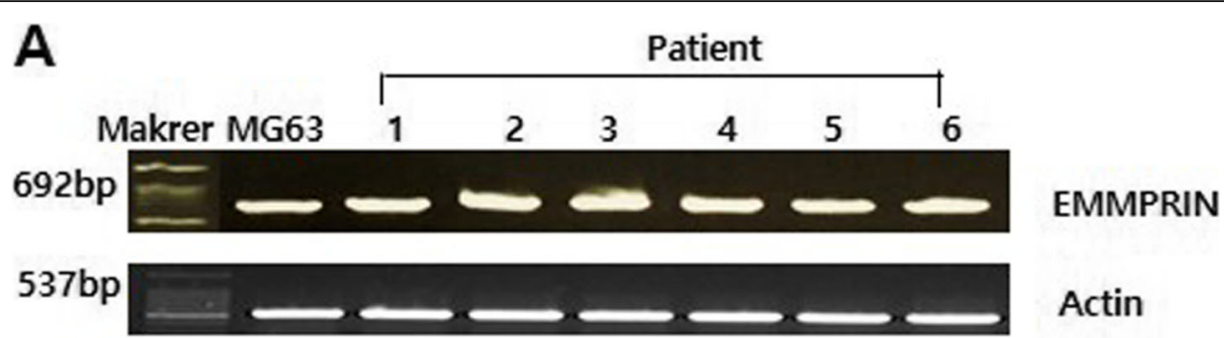

B

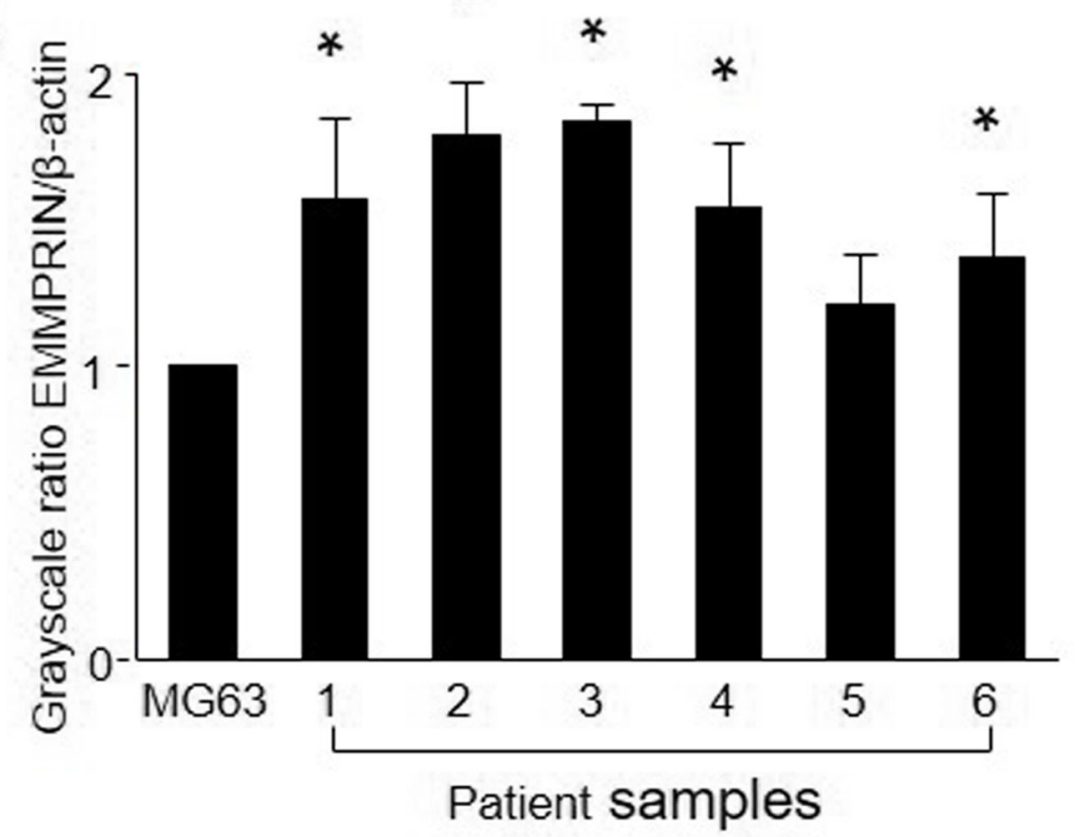

C

MarkerControl 10nM 20nM 30nM
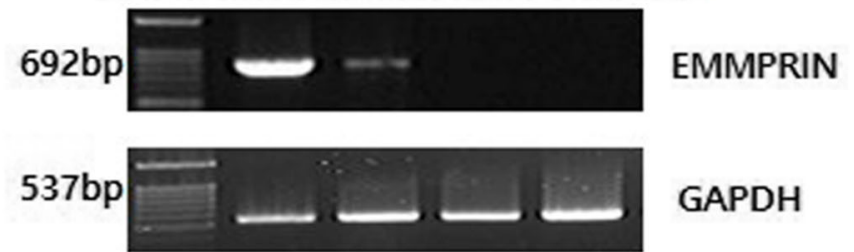

GAPDH

D

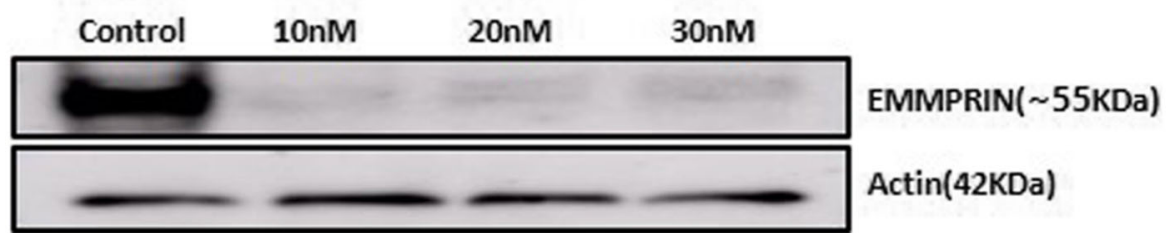

Fig. 1 (See legend on next page.) 
(See figure on previous page.)

Fig. 1 EMMPRIN expression in osteosarcoma by reverse transcription-PCR and Western blot. a Reverse transcription-PCR products of total RNA in tumor-derived osteosarcoma cells from 6 patients. b Comparison of grayscale ratio of EMMPRIN/ $\beta$-actin in tumor-derived osteosarcoma cells and MG63. *, $p<0.05$ compared with MG63. c EMMPRIN mRNA expression after transfection of SaOS-2 cell by EMMPRIN-targeting siRNA. Data shown are representative images of individual cell lines from three separate experiments. $\mathbf{d}$ Western blot analysis of EMMPRIN protein expressions. $\beta$ actin was used as loading control
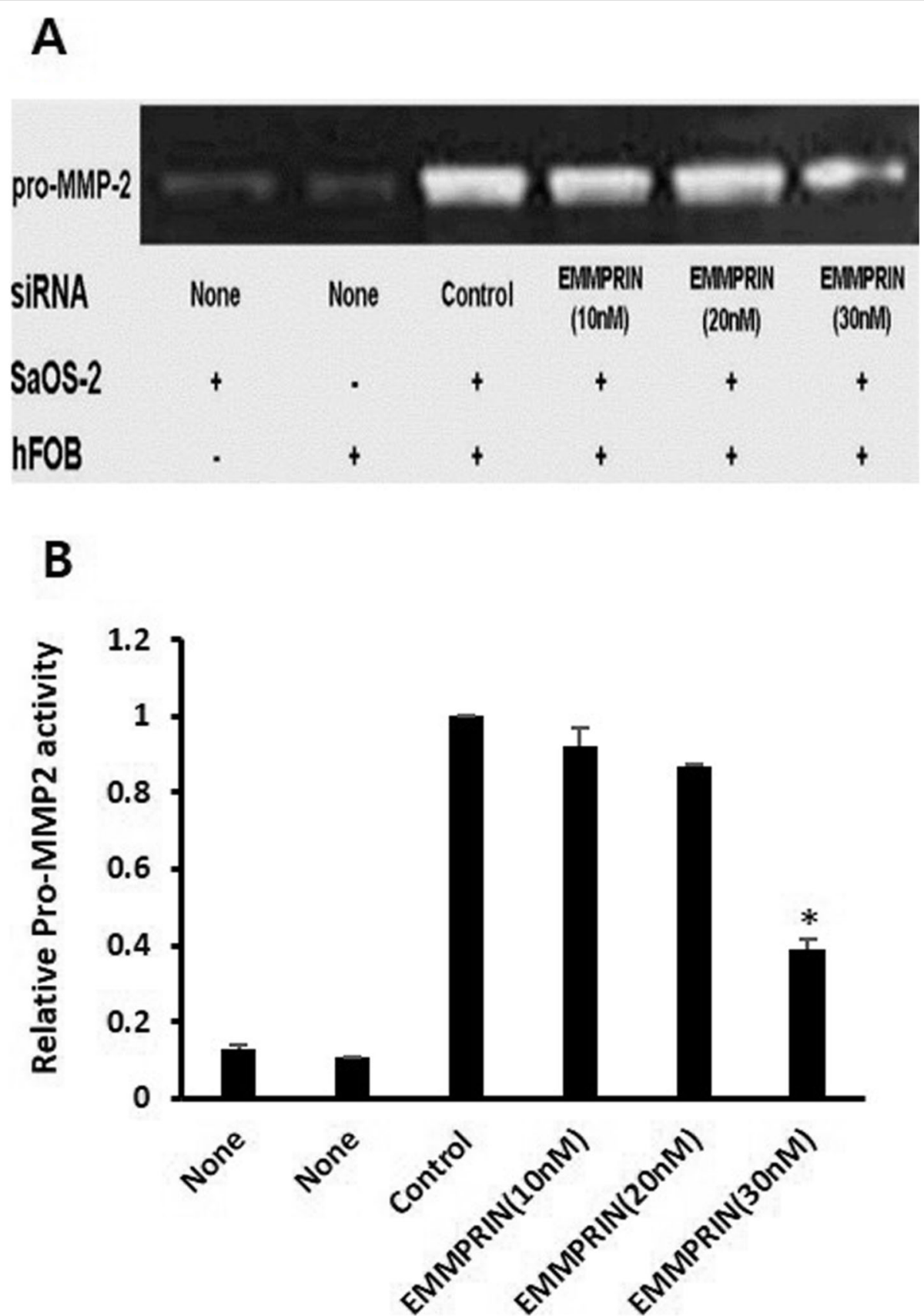

Fig. 2 Reversal of MMP2 stimulation in co-cultures of SaOS-2 and osteoblast by EMMPRIN siRNA transfection. a SaOS-2 and osteoblast showed weak gelatinolytic band for pro-MMP2 when cultured alone (Lanes 1, 2). When osteoblast and SaOS-2 were co-cultured, enhanced stimulation of pro-MMP2 was observed (Lane 3). This stimulation was reversed by transfection of SaOS-2 with EMMPRIN-targeting siRNA (Lanes 4-6). Data shown are representative images of individual cell lines from three separate experiments. $\mathbf{b}$ Comparison of grayscale ratio of gelatinolytic band for pro-MMP2 ${ }^{*}, p<0.05$ compared with control 


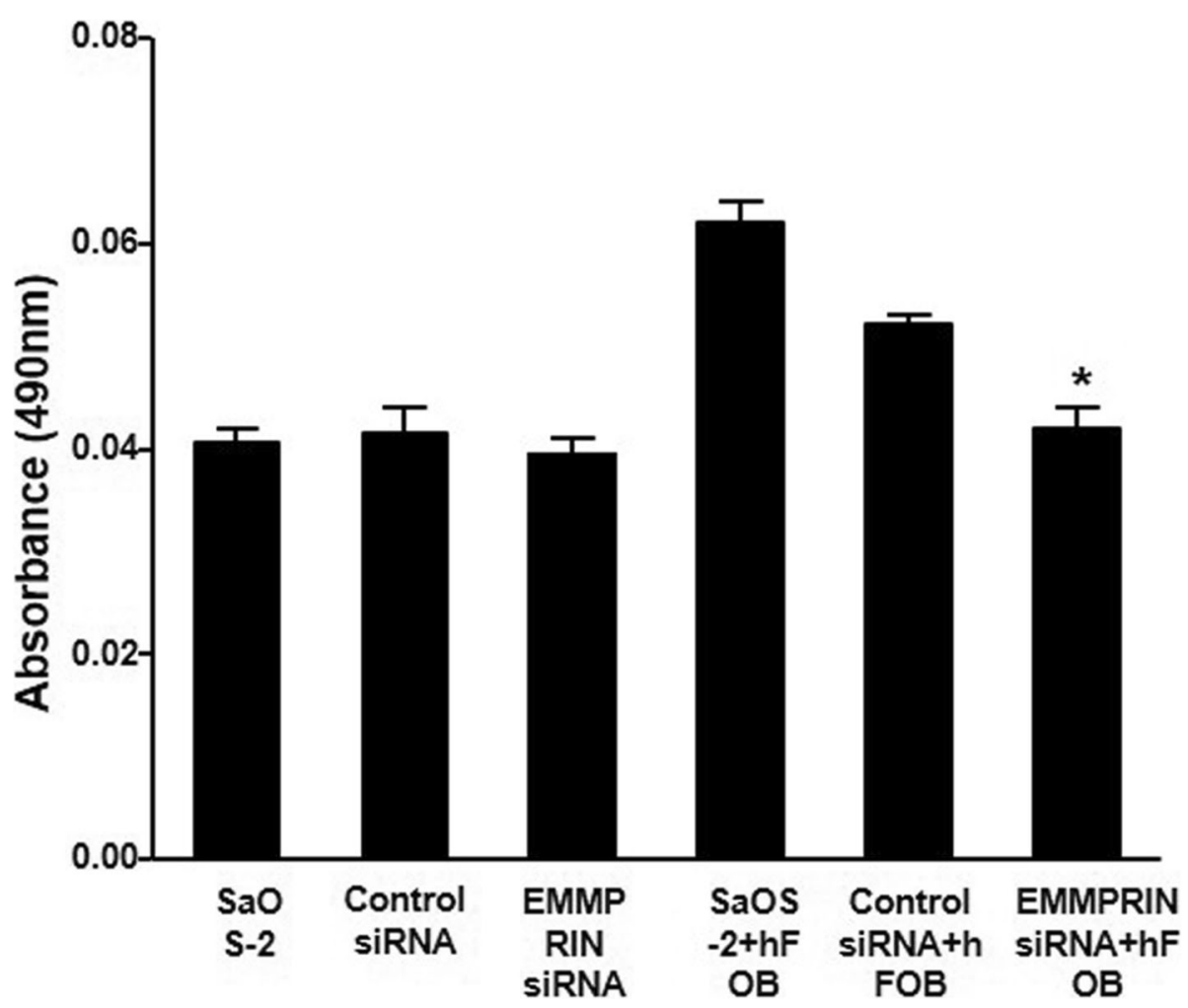

Fig. 3 Decrease of VEGF production in co-cultures of SaOS-2 and osteoblast by EMMPRIN siRNA transfection. When osteoblasts and SaOS-2 cells were co-cultured, VEGF expression was increased compared to the SaOS-2-only culture. Transfection of SaOS-2 cells with EMMPRIN-targeting siRNA resulted in a decrease in VEGF expression. ${ }^{*} p<0.05$ compared with cells transfected with control siRNA

EMMPRIN silencing and metastatic potential in vivo

The tumor volume was significantly reduced in EMMP RIN shRNA transfected 143B cells as compared to the corresponding mock shRNA transfected 143B cells in vivo $\left(5.3 \pm 1.2 \mathrm{~mm}^{3}\right.$ vs. $\left.20.9 \pm 3.9 \mathrm{~mm}^{3}, p=0.002\right)$ (Fig. 5A,B) The number of nodules was also reduced in EMMPRIN shRNA transfected cells $(13.2 \pm 2.00$ vs. $27.0 \pm 3.0, p=0.001$ ) (Fig. 5A,C). These results show that EMMPRIN regulates lung metastasis in osteosarcoma. We used shRNAs to show that EMMPRIN expression was significantly decreased in 143B cells by western blotting (Fig. 5D), whereas its mock shRNA enhanced protein production in $143 \mathrm{~B}$ cells. $\mathrm{H} \& \mathrm{E}$ staining showed typical tumor morphologies, that is, the nuclei were large, deeply stained, and the cells were closely arranged in vivo (Fig. 5E).

\section{EMMPRIN expression and clinical outcome}

Osteosarcoma cells showed strong positivity for EMMP RIN with accentuation along the cell membrane. EMMP RIN was expressed in $96 \%$ of cells $(n=50)$ as indicated by immunohistochemistry (Fig. 6A, B). Of the 52 cases, 10 (19\%) showed the EMMPRIN expression of more than $50 \%$ of the tumor cells (high expression) and 42 cases (81\%) less than $50 \%$ (low expression). Of the 10 cases with high expression, 7 patients developed metastases, whereas only 13 of 42 cases with low expression developed metastases. Patients with high EMMPRIN expression had significantly worse metastasis-free survival $(p=0.023)$ (Fig. 6D).

\section{Discussion}

In our study, we verified the protein expression mechanism of EMMPRIN, MMP2, and VEGF in osteosarcoma by immunohistochemical staining and molecular experiments, and characterized the expression patterns of EMMPRIN with the help of clinicopathological discoveries and recurrence-free survival in 52 patients with osteosarcoma. Moreover, the expression of EMMPRIN, as shown by immunohistochemistry, was examined in 90\% of osteosarcoma tissues. Patients with high EMMP RIN expression had significantly worse metastasis-free survival. This finding was consistent with the results for other human tumors [18, 24, 25]. In line with our study, Zhou et al. reported that expression of EMMPRIN was detected in $70 \%$ of patients with osteosarcoma. EMMR PIN levels were elevated in ostesarcoma patients with advanced disease and worse response to chemotherapy as compared to those with less advanced stage and better response to chemotherapy [23]. Variable expression 


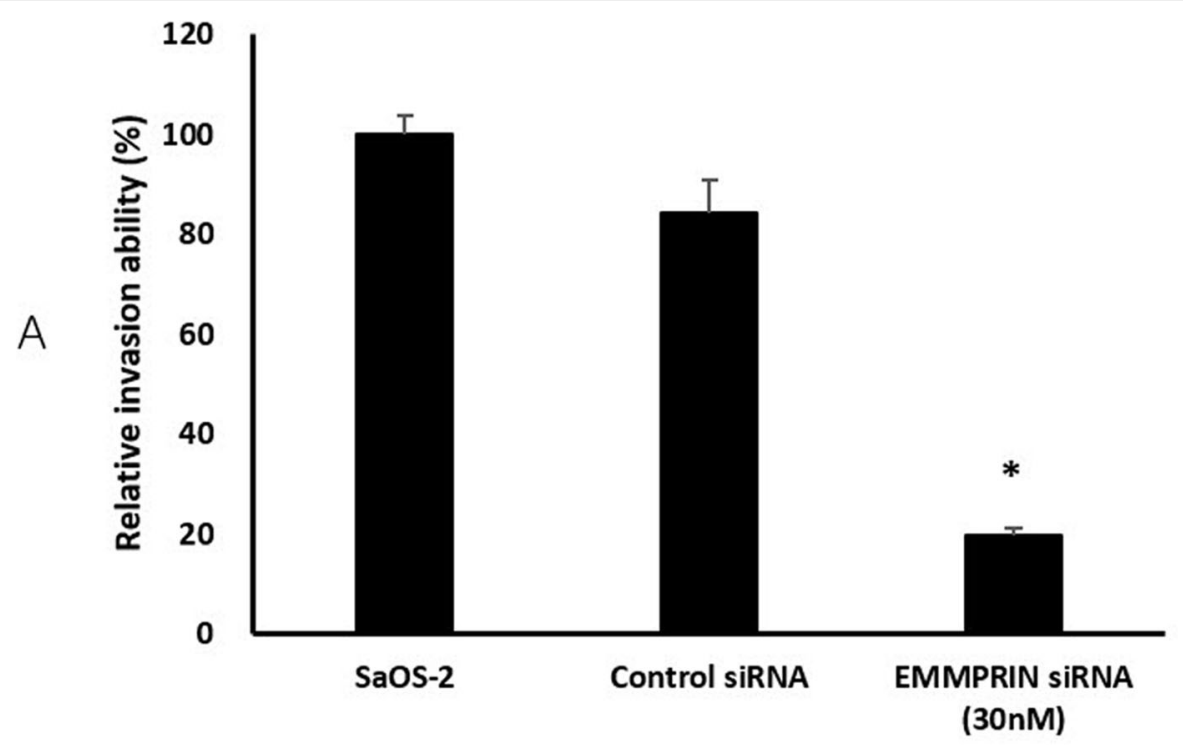

B
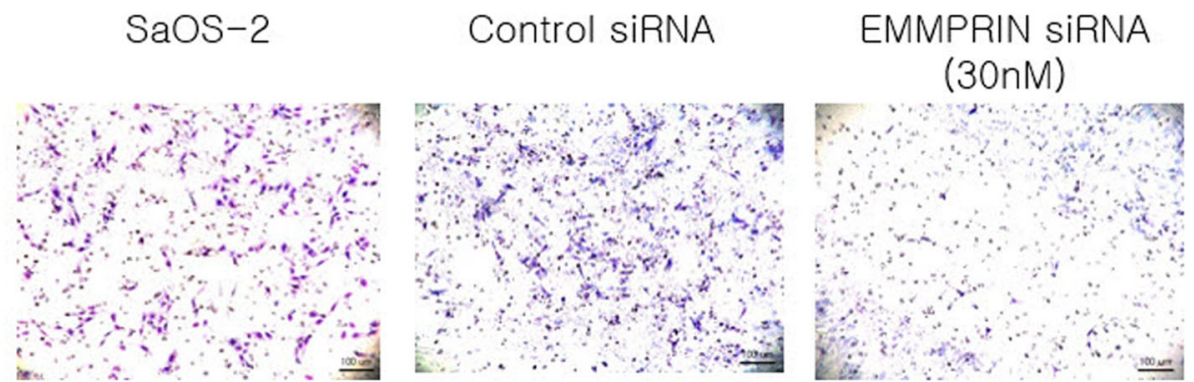

Fig. 4 Decrease in invasion activities of SaOS-2 cells transfected by EMMPRIN siRNA. Matrigel invasion assays after transfection of the EMMRIN siRNA into SaOS-2 cells for $24 \mathrm{~h}$. Following incubation, the membranes were removed from the inserts and mounted on slides. a. The number of invading cells was counted under a light microscope. The Matrigel assay was performed in triplicates. ${ }^{*} p<0.05$ compared with cells transfected with control siRNA. b. Representative images of Matrigel invasion assay. Scale bar, $100 \mu \mathrm{m}$

of EMMPRIN was found in $65 \%$ of human prostate cancer tissues and correlated significantly with progression parameters [24]. Increased expression of EMMPRIN was monitored in primary oral squamous cell carcinoma and metastatic oral squamous cell carcinoma specimens. Moreover, a strong EMMPRIN expression was found in more than $90 \%$ of the cells in the carcinomas-insitu and early invasive squamous cell carcinoma [25]. Several studies have reported high levels of EMMP RIN expression is involved in many cancers [13, 2636]. EMMPRIN expression has been also considered as a marker of a poor prognosis for breast cancer patients [34]. Ueda et al. demonstrated that high EMMP RIN expression was associated with more recurrence in endometrial cancer [35].

It is widely noted that angiogenesis in the EMMPRINMMP-VEGF system has a significant role in tumor progression by cancer stroma interaction [37]. Recent studies have shown that VEGF and MMP production are stimulated immediately by elevated EMMPRIN expression in tumor cells as well as stromal cells in breast cancer [38]. Moreover, to regulate VEGF production in an MMP-dependent manner, in vivo soluble VEGF is increased or biologically active angiogenic growth factor is released by tumor-derived MMP [18]. Cell adhesion, cytoskeleton reorganization, and cell invasion in prostate cancer cells are controlled by EMMPRIN [36]. In bladder, prostate, and gastric cancer, a significant inhibitory effect is exhibited when transfected with EMMPRIN siRNA [13, 39, 40]. In this study, the suppression of cell proliferation, invasion, and metastasis in osteosarcoma specimens was demonstrated after the transfection of the EMMPRIN siRNA. We observed that EMMPRIN knockdown inhibited the secretion of MMP2, the expression of VEGF, and invasion and metastasis of osteosarcoma. The results are consistent with other reports 
A

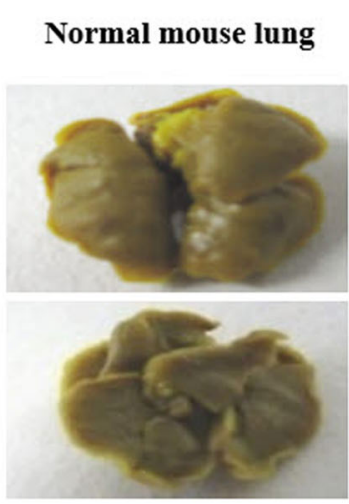

143B -ad mock shRNA vector

\section{B -ad EMMPRIN ShRNA vector}

Front
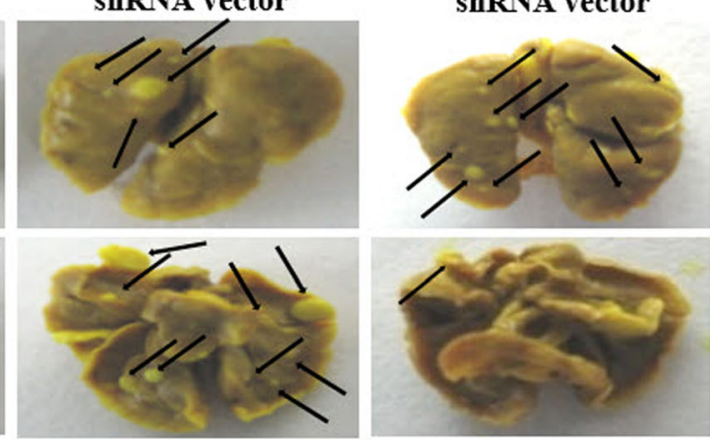

Back

\section{B}

\section{C}
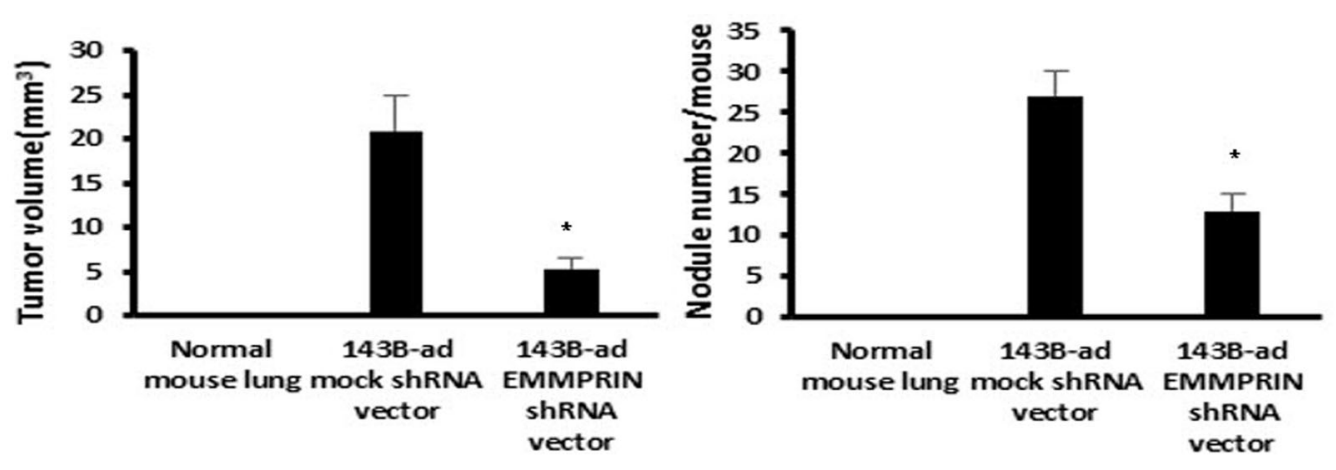

D

$\begin{array}{ccc}\text { Normal } & \text { 143B ad mock } & \text { 143B-ad EMMPRIN } \\ \text { mouse lung } & \text { shRNA } & \text { shRNA vector }\end{array}$

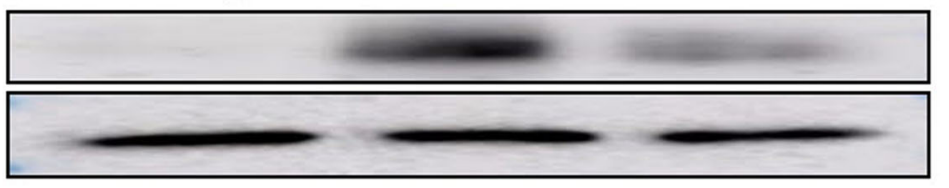

$\rightarrow \underset{\text { ( }}{\rightarrow \text { 55KDM })}$

$\rightarrow$ Actin

(45KDa)

E

Normal mouse lung

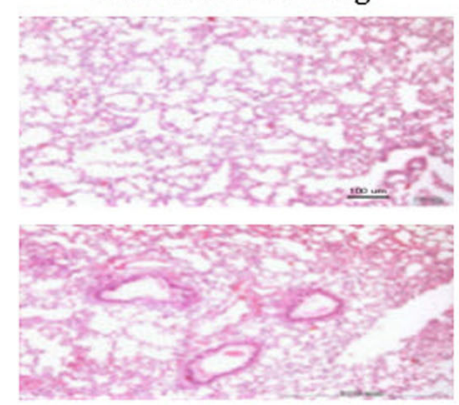

143B -ad mock shRNA vector

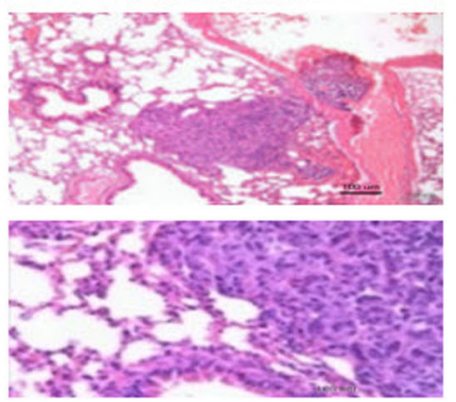

143B -ad EMMPRIN

ShRNA vector

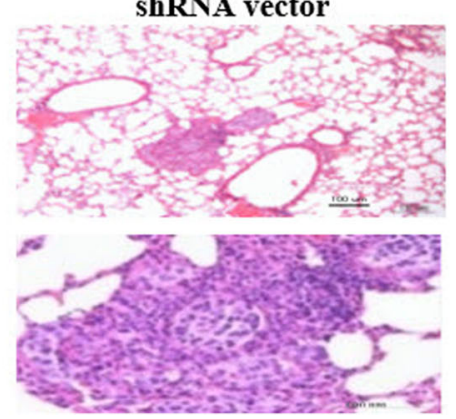

Fig. 5 (See legend on next page.) 
(See figure on previous page.)

Fig. 5 EMMPRIN silencing inhibits the metastatic nodes in the lungs. a Metastasis assay by tail vein injection of shRNA transfected 143B cells in BALB/c mice. Lungs were excised for examination at 8 weeks post-injection. The number of lung metastatic nodes was assessed by Bouin's stain. Arrows indicate visible lung surface metastases. b Tumor volume and $\mathbf{c}$ Number of nodules at the study end point. $\mathbf{d}$ 143B cells were transfected with mock shRNA and EMMPRIN shRNA for $48 \mathrm{~h}$, and cell lysates were analyzed by western blot using anti-EMMPRIN antibody. $\beta$-actin was used as a loading control. e Microscope images by H\&E staining show that EMMPRIN silencing significantly inhibits the lung metastatic nodes after inoculation with $143 \mathrm{~B}, 2 \times 10^{5}$ cells/ 200 ul. *, $p<0.05$ compared with cells transfected with control siRNA. Scale bar, $100 \mu \mathrm{m}$. Original magnification, $\times 10$ and $\times 40$

suggesting the inactivation of MMP2 and VEGF by EMMPRIN knockdown inhibits cancer migration and invasion [40-42]. Indeed, in our study, EMMPRIN-targeting siRNA inhibited proliferation and invasion of osteosarcoma cells.

To examine the effect of EMMPRIN silencing on osteosarcoma cell metastasis, we injected EMMPRIN shRNA transfected 143B cells in nude mice and assessed the presence of metastatic nodules in the lung. The EMMPRIN shRNA vector suppressed the expression of EMMPRIN in pancreatic cancer cells, reducing the invasion and metastasis in vitro and in vivo [43]. The expression of EMMPRIN mRNA and protein in MCF-7 cells was reduced with the EMMPRIN-shRNA lentivirus, which has been verified through EMMPRIN shRNA in breast cancer [44]. The expression levels of EMMPRIN mRNA and protein in MCF-7 cells were significantly decreased after infection with the EMMPRIN-shRNA lentivirus, which was proven through EMMPRIN shRNA in breast cancer MCF-7 cells using the lentivirus-induced RNAi technique to investigate the changes in breast cancer proliferation potential under conditions of EMMP
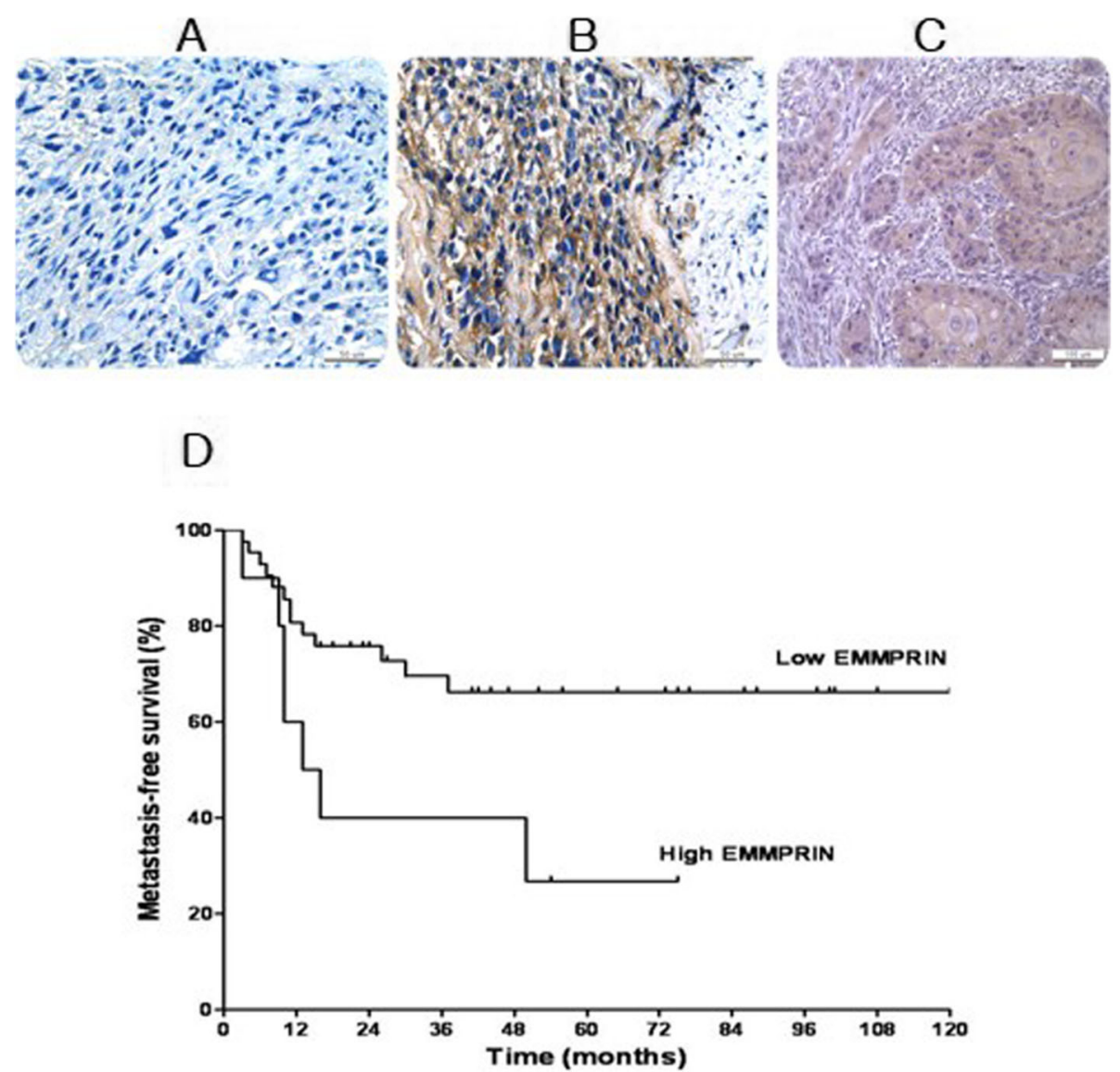

Fig. 6 EMMPRIN expression in osteosarcoma by immunohistochemical staining and metastasis-free survival. Representative case for a low EMMP RIN expression. b high EMMPRIN expression and c esophageal cancer, a positive control. Scale bar, 50 um. d Metastasis-free survival of 52 patients with osteosarcoma in relation to EMMPRIN expression. The survival time in individual patients was determined and the survival curves of patients with different expression of EMMPRIN were generated by Kaplan-Meier method 
RIN gene deletion. Li et al. used an shRNA vector to lower EMMPRIN expression in the colorectal cancer cell line HT29 and found that levels of EMMPRIN mRNA and protein were reduced in vitro and in vivo [45]. Lung metastases are associated with poor prognosis in patients with osteosarcoma. The underlying molecular mechanisms of lung metastasis remain to be elucidated. In the present study, we found that knockdown of EMMPRIN inhibited lung metastasis.

\section{Conclusions}

In conclusion, EMMPRIN overexpression may play an important role in the metastasis of osteosarcoma and could be a potential therapeutic target of osteosarcoma.

\section{Abbreviations}

OS: Osteosarcoma; ECM: Extracellular matrix; MMPs: Matrix metalloproteinase proteins; TIMPs: Tissue inhibitors of metalloproteinases; EMMP RIN: Extracellular matrix metalloproteinase inducer; VEGF: Vascular endothelial growth factor; RT-PCR: Reverse transcriptase polymerase chain reaction

\section{Acknowledgements}

Not applicable.

\section{Authors' contributions}

The study was designed by HSK and IH. Sample collection and experimental work were performed by HSK, MRL, and IH. Data were analyzed and interpretated by HSK, HJK, MRL, and $\mathrm{H}$. The manuscript was written by HSK, $\mathrm{HJK}$, and $\mathrm{IH}$. All authors read and approved the final manuscript.

\section{Funding}

The authors declare that they have nothing to disclose. This study was supported by National Research Foundation of Korea Grant funded by the Korean Government (Grant no. 2009-0136) and Doosan Yonkang Foundation (Grant no. 30-2014-0120). The funding body had no role in the design of the study and collection, analysis, and interpretation of data and in writing this manuscript.

\section{Availability of data and materials}

The datasets used and/or analysed during the current study are available from the corresponding author on reasonable request.

\section{Declarations}

\section{Ethics approval and consent to participate}

The Seoul National University Hospital and Seoul National University College of Medicine institutional review board granted approval to this study (approval number E-1405-012-577). The IRB has determined that informed consent from individual patients was not necessary for this study. All animal experiments were undertaken according to the national guideline in Korea. All protocols were approved by the Institutional Animal Care and Use Committee of Seoul National University Hospital (approval number 10-0075).

\section{Consent for publication}

Not applicable.

\section{Competing interests}

The authors declare that they have no competing interests.

Received: 17 January 2021 Accepted: 10 September 2021

Published online: 26 September 2021

\section{References}

1. Moirangthem A, Bondhopadhyay B, Mukherjee M, Bandyopadhyay A, Mukherjee N, Konar K, et al. Simultaneous knockdown of UPA and MMP9 can reduce breast cancer progression by increasing cell-cell adhesion and modulating EMT genes. Sci Rep. 2016;6(1):21903. https://doi.org/10.1038/ srep21903.

2. Jones KB, Salah Z, Del Mare S, Galasso M, Gaudio E, Nuovo GJ, et al. miRNA signatures associate with pathogenesis and progression of osteosarcoma. Cancer Res. 2012;72(7):1865-77. https://doi.org/10.1158/0008-5472.CAN-11-2 663.

3. Gibbs CP, Kukekov VG, Reith JD, Tchigrinova O, Suslov ON, Scott EW, et al. Stem-like cells in bone sarcomas: implications for tumorigenesis. Neoplasia. 2005;7(11):967-76. https://doi.org/10.1593/neo.05394.

4. Meyers PA, Healey JH, Chou AJ, Wexler LH, Merola PR, Morris CD, et al. Addition of pamidronate to chemotherapy for the treatment of osteosarcoma. Cancer. 2011;117(8):1736-44. https://doi.org/10.1002/cncr.2 5744.

5. Kansara M, Teng MW, Smyth MJ, Thomas DM. Translational biology of osteosarcoma. Nat Rev Cancer. 2014;14(11):722-35. https://doi.org/10.1038/ $\operatorname{nrc3838.}$

6. Lu J, Song G, Tang Q, Zou C, Han F, Zhao Z, et al. IRX1 hypomethylation promotes osteosarcoma metastasis via induction of CXCL14/NF-kappaB signaling. J Clin Invest. 2015;125(5):1839-56. https://doi.org/10.1172/JCI78437.

7. Hou CH, Lin FL, Hou SM, Liu JF. Cyr61 promotes epithelial-mesenchymal transition and tumor metastasis of osteosarcoma by Raf-1/MEK/ERK/Elk-1/ TWIST-1 signaling pathway. Mol Cancer. 2014;13(1):236. https://doi.org/10.11 86/1476-4598-13-236.

8. Tsai HC, Su HL, Huang CY, Fong YC, Hsu CJ, Tang CH. CTGF increases matrix metalloproteinases expression and subsequently promotes tumor metastasis in human osteosarcoma through down-regulating miR-519d. Oncotarget. 2014;5(11):3800-12. https://doi.org/10.18632/oncotarget.1998.

9. Fogh J, Fogh JM, Orfeo T. One hundred and twenty-seven cultured human tumor cell lines producing tumors in nude mice. J Natl Cancer Inst. 1977; 59(1):221-6. https://doi.org/10.1093/jnci/59.1.221.

10. Harris SA, Enger RJ, Riggs BL, Spelsberg TC. Development and characterization of a conditionally immortalized human fetal osteoblastic cell line. J Bone Mineral Res. 1995;10(2):178-86. https://doi.org/10.1002/jbmr. 5650100203.

11. Billiau A, Edy VG, Heremans H, Van Damme J, Desmyter J, Georgiades JA, et al. Human interferon: mass production in a newly established cell line, MG-63. Antimicrob Agents Chemother. 1977;12(1):11-5. https://doi.org/1 0.1128/AAC.12.1.11.

12. Kang HG, Kim HS, Kim KJ, Oh JH, Lee MR, Seol SM, et al. RECK expression in osteosarcoma: correlation with matrix metalloproteinases activation and tumor invasiveness. J Orthop Res. 2007;25(5):696-702. https://doi.org/10.1 002/jor.20323.

13. Xue YJ, Lu Q, Sun ZX. CD147 overexpression is a prognostic factor and a potential therapeutic target in bladder cancer. Med Oncol. 2011;28(4):136372. https://doi.org/10.1007/s12032-010-9582-4

14. Birkedal-Hansen H, Moore WG, Bodden MK, Windsor LJ, Birkedal-Hansen B, DeCarlo A, et al. Matrix metalloproteinases: a review. Crit Rev Oral Biol Med. 1993;4(2):197-250. https://doi.org/10.1177/10454411930040020401.

15. Aresu L, Aricò A, Comazzi S, Gelain ME, Riondato F, Mortarino M, et al. VEGF and MMP-9: biomarkers for canine lymphoma. Vet Comp Oncol. 2014;12(1): 29-36. https://doi.org/10.1111/j.1476-5829.2012.00328.x.

16. Bjørnland K, Flatmark K, Pettersen S, Aaasen AO, Fodstad O, Maelandsmo GM. Matrix metalloproteinases participate in osteosarcoma invasion. J Surg Res. 2005;127(2):151-6.

17. Rosen G, Caparros B, Huvos AG, Kosloff C, Nirenberg A, Cacavio A, et al. Preoperative chemotherapy for osteogenic sarcoma: selection of postoperative adjuvant chemotherapy based on the response of the primary tumor to preoperative chemotherapy. Cancer. 1982;49(6):1221-30. https://doi.org/10.1002/1097-0142(19820315)49:6<1221::AID-CNCR282049062 5>3.0.CO;2-E.

18. Zhou Q, Zhu Y, Deng Z, Long H, Zhang S, Chen X. VEGF and EMMPRIN expression correlates with survival of patients with osteosarcoma. Surg Oncol. 2011;20(1):13-9. https://doi.org/10.1016/j.suronc.2009.09.002.

19. Delyon J, Khayati F, Djaafri I, Podgorniak M, Sadoux A, Setterblad N, et al. EMMPRIN regulates $\beta 1$ integrin-mediated adhesion through Kindlin-3 in human melanoma cells. Exp Dermatol. 2015;24(6):443-8. https://doi.org/1 $0.1111 /$ exd.12693

20. Jensen MM, Jørgensen JT, Binderup T, Kjaer A. Tumor volume in subcutaneous mouse xenografts measured by microCT is more accurate and reproducible than determined by $18 \mathrm{~F}-\mathrm{FDG}$-microPET or external caliper. BMC Med Imaging. 2008;8(1):16. https://doi.org/10.1186/1471-2342-8-16. 
21. Han I, Lee MR, Nam KW, Oh JH, Moon KC, Kim HS. Expression of macrophage migration inhibitory factor relates to survival in high-grade osteosarcoma. Clin Orthop Relat Res. 2008;466(9):2107-13. https://doi.org/1 0.1007/s11999-008-0333-1.

22. Ishibashi Y, Matsumoto T, Niwa M, Suzuki Y, Omura N, Hanyu N, et al. CD147 and matrix metalloproteinase-2 protein expression as significant prognostic factors in esophageal squamous cell carcinoma. Cancer. 2004; 101(9):1994-2000. https://doi.org/10.1002/cncr.20593.

23. Sinclair W, Kobalka P, Ren R, Beshai B, Lott Limbach AA, Wei L, et al Interobserver agreement in programmed cell death-ligand 1 immunohistochemistry scoring in nonsmall cell lung carcinoma cytologic specimens. Diagn Cytopathol. 2021;49(2):219-25. https://doi.org/10.1002/ dc.24651.

24. Madigan MC, Kingsley EA, Cozzi PJ, Delprado WJ, Russell PJ, Li Y. The role of extracellular matrix metalloproteinase inducer protein in prostate cancer progression. Cancer Immunol Immunother. 2008;57(9):1367-79. https://doi. org/10.1007/s00262-008-0473-x.

25. Vigneswaran N, Beckers S, Waigel S, Mensah J, Wu J, Mo J, et al. Increased EMMPRIN (CD 147) expression during oral carcinogenesis. Exp Mol Pathol. 2006;80(2):147-59. https://doi.org/10.1016/j.yexmp.2005.09.011.

26. Jin JS, Yao CW, Loh SH, Cheng MF, Hsieh DS, Bai CY. Increasing expression of extracellular matrix metalloprotease inducer in ovary tumors: tissue microarray analysis of immunostaining score with clinicopathological parameters. Int J Gynecol Pathol. 2006;25(2):140-6. https://doi.org/10.1097/ 01.pgp.0000189244.57145.84.

27. Sameshima T, Nabeshima K, Toole BP, Yokogami K, Okada Y, Goya T, et al. Expression of emmprin (CD147), a cell surface inducer of matrix metalloproteinases, in normal human brain and gliomas. Int J Cancer. 2000; 88(1):21-7. https://doi.org/10.1002/1097-0215(20001001)88:1<21::AID-IJC4>3. $0 . \mathrm{CO} ; 2-\mathrm{S}$.

28. Zheng HC, Takahashi H, Murai Y, Cui ZG, Nomoto K, Miwa S, et al. Upregulated EMMPRIN/CD147 might contribute to growth and angiogenesis of gastric carcinoma: a good marker for local invasion and prognosis. Br J Cancer. 2006;95(10):1371-8. https://doi.org/10.1038/sj.bjc. 6603425.

29. Bordador LC, Li X, Toole B, Chen B, Regezi J, Zardi L, et al. Expression of emmprin by oral squamous cell carcinoma. Int J Cancer. 2000;85(3):347-52 https://doi.org/10.1002/(SICI)1097-0215(20000201)85:3<347::AID-IJC9>3.0. CO;2-\#.

30. Kanekura T, Chen X, Kanzaki T. Basigin (CD147) is expressed on melanoma cells and induces tumor cell invasion by stimulating production of matrix metalloproteinases by fibroblasts. Int J Cancer. 2002;99(4):520-8. https://doi. org/10.1002/ijc.10390.

31. Li Y, Xu J, Chen L, Zhong WD, Zhang Z, Mi L, et al. HAb18G (CD147), a cancer-associated biomarker and its role in cancer detection. Histopathology. 2009;54(6):677-87. https://doi.org/10.1111/j.1365-2559.2009. 03280.x.

32. Zhang Q, Zhou J, Ku XM, Chen XG, Zhang L, Xu J, et al. Expression of CD147 as a significantly unfavorable prognostic factor in hepatocellular carcinoma. Eur J Cancer Prev. 2007;16(3):196-202. https://doi.org/10.1097/01. cej.0000236245.40619.c3.

33. Tan H, Ye K, Wang Z, Tang H. CD147 expression as a significant prognostic factor in differentiated thyroid carcinoma. Transl Res. 2008;152(3):143-9. https://doi.org/10.1016/j.trsl.2008.07.005.

34. Reimers N, Zafrakas K, Assmann V, Egen C, Riethdorf L, Riethdorf S, et al. Expression of extracellular matrix metalloproteases inducer on micrometastatic and primary mammary carcinoma cells. Clin Cancer Res. 2004;10(10):3422-8. https://doi.org/10.1158/1078-0432.CCR-03-0610.

35. Ueda K, Yamada K, Urashima M, Ishibashi Y, Shirai M, Nikaido T, et al. Association of extracellular matrix metalloproteinase inducer in endometrial carcinoma with patient outcomes and clinicopathogenesis using monoclonal antibody 12C3. Oncol Rep. 2007;17(4):731-5. https://doi.org/1 0.3892/or.17.4.731.

36. Zhu H, Zhao J, Zhu B, Collazo J, Gal J, Shi P, et al. EMMPRIN regulates cytoskeleton reorganization and cell adhesion in prostate cancer. Prostate. 2012;72(1):72-81. https://doi.org/10.1002/pros.21408.

37. Sounni NE, Roghi C, Chabottaux V, Janssen M, Munaut C, Maquoi E, et al. Up-regulation of vascular endothelial growth factor-a by active membranetype 1 matrix metalloproteinase through activation of Src-tyrosine kinases. J Biol Chem. 2004;279(14):13564-74. https://doi.org/10.1074/jbc.M307688200.
38. Tang Y, Nakada MT, Kesavan P, McCabe F, Millar H, Rafferty P, et al. Extracellular matrix metalloproteinase inducer stimulates tumor angiogenesis by elevating vascular endothelial cell growth factor and matrix metalloproteinases. Cancer Res. 2005;65(8):3193-9. https://doi.org/10.1158/ 0008-5472.CAN-04-3605.

39. Wang B, Xu YF, He BS, Pan YQ, Zhang LR, Zhu C, et al. RNAi-mediated silencing of CD147 inhibits tumor cell proliferation, invasion and increases chemosensitivity to cisplatin in SGC7901 cells in vitro. J Exp Clin Cancer Res. 2010;29(1):61. https://doi.org/10.1186/1756-9966-29-61.

40. Wang L, Wu G, Yu L, Yuan J, Fang F, Zhai Z, et al. Inhibition of CD147 expression reduces tumor cell invasion in human prostate cancer cell line via RNA interference. Cancer Biol Ther. 2006;5(6):608-14. https://doi.org/1 0.4161/cbt.5.6.2661.

41. Bougatef F, Menashi S, Khayati F, Naimi B, Porcher R, Podgorniak MP, et al. EMMPRIN promotes melanoma cells malignant properties through a HIF2alpha mediated up-regulation of VEGF-receptor-2. PLoS One. 2010;5(8): e12265. https://doi.org/10.1371/journal.pone.0012265.

42. Biswas C, Zhang Y, DeCastro R, Guo H, Nakamura T, Kataoka H, et al. The human tumor cell-derived collagenase stimulatory factor (renamed EMMP $\mathrm{RIN}$ ) is a member of the immunoglobulin superfamily. Cancer Res. 1995; 55(2):434-9.

43. Pan Y, He B, Song G, Bao Q, Tang Z, Tian F, et al. CD147 silencing via RNA interference reduces tumor cell invasion, metastasis and increases chemosensitivity in pancreatic cancer cells. Oncol Rep. 2012;27(6):2003-9. https://doi.org/10.3892/or.2012.1729.

44. Yang J, Wang R, Li H, Lv Q, Meng W, Yang X. Lentivirus mediated RNA interference of EMMPRIN (CD147) gene inhibits the proliferation, matrigel invasion and tumor formation of breast cancer cells. Cancer Biomark. 2016; 17(2):237-47. https://doi.org/10.3233/CBM-160636.

45. Li R, Pan Y, He B, Xu Y, Gao T, Song G, et al. Downregulation of CD147 expression by RNA interference inhibits HT29 cell proliferation, invasion and tumorigenicity in vitro and in vivo. Int J Oncol. 2013;43(6):1885-94. https:// doi.org/10.3892/ijo.2013.2108.

\section{Publisher's Note}

Springer Nature remains neutral with regard to jurisdictional claims in published maps and institutional affiliations.
Ready to submit your research? Choose BMC and benefit from:

- fast, convenient online submission

- thorough peer review by experienced researchers in your field

- rapid publication on acceptance

- support for research data, including large and complex data types

- gold Open Access which fosters wider collaboration and increased citations

- maximum visibility for your research: over $100 \mathrm{M}$ website views per year

At BMC, research is always in progress.

Learn more biomedcentral.com/submissions 